\title{
Intakes of total fat, saturated, monounsaturated and polyunsaturated fatty acids in Irish children, teenagers and adults
}

\author{
Triona Joyce, Alison J Wallace, Sinead N McCarthy and Michael J Gibney* \\ UCD Institute of Food and Health, University College Dublin, Dublin 4, Ireland
}

Submitted 7 September 2007: Accepted 12 March 2008: First published online 25 November 2008

\begin{abstract}
Recommendations limiting the intake of total fat, SFA, MUFA and PUFA have been established in several countries with the aim of reducing the risk of chronic diseases such as CVD. Studies have shown that intakes of total fat and SFA are above desired recommended intake levels across a wide range of age and sex groups. In addition, intakes of PUFA and MUFA are often reported to be less than the desired recommended intake levels. The aims of the present paper are to provide the first data on estimates of current intakes and main food sources of SFA, MUFA and PUFA in Irish children (aged 5-12 years), teenagers (aged 13-17 years) and adults (aged 18-64 years) and to analyse compliance with current dietary recommendations. Data for this analysis were based on the North/ South Ireland Food Consumption Survey ( $n$ 1379, 18-64 years), the National Children's Food Survey ( $n$ 594, 5-12 years) and the National Teen Food Survey ( $n$ 441, 13-17 years). Results showed that SFA intakes in Irish children, teenagers and adults are high, with only $6 \%$ of children, $11 \%$ of teenagers and $21 \%$ of adults in compliance with the recommended daily intake. The main food groups that contributed to SFA intakes were whole milk; fresh meat; meat products; biscuits, cakes, buns and pastries; and sugars, confectionery and preserves.
\end{abstract}

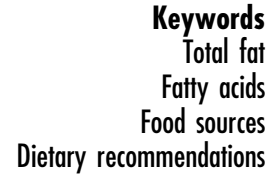

Total fat

Fatty acids Dietary recommendations
It has been well established that diet is closely linked to health and disease. Numerous studies have reported a link between dietary fat intake and CVD. In the Republic of Ireland alone, CVD is among the leading causes of mortality accounting for $36 \%$ of all deaths in $2005^{(1)}$. Total fat and saturated fat (SFA) intakes are associated with increased risk of CVD while polyunsaturated fat (PUFA) may decrease the risk of $\mathrm{CVD}^{(2)}$. The ratio of PUFA : SFA (P:S ratio) is of particular importance in relation to the development of CVD. In their report Dietary Reference Values for the Food Energy and Nutrients for the United Kingdom, the UK Department of Health ${ }^{(3)}$ recommended that the P:S ratio should be between 0.23 and 0.45 . Furthermore, it has been reported that the development of atherosclerosis, a risk factor for CVD, begins in child$\operatorname{hood}^{(4)}$. Unhealthy lifestyles and behaviours also begin in childhood, such as excess intakes of energy and saturated fat, inactivity and obesity ${ }^{(4)}$. Therefore, advice to reduce CVD rates needs to target all age groups in the population.

As high fat intakes are an established risk factor for several chronic diseases such as CVD, recommendations on fat intakes have been established in several countries. In the UK the Department of Health ${ }^{(3)}$ recommends a maximum intake from total fat and SFA of $33 \%$ and $10 \%$ of total energy, respectively. Numerous studies have shown that intakes of total fat ${ }^{(1,5-9)}$ and $\mathrm{SFA}^{(8-12)}$ are above desired recommended intake levels across a wide range of age and sex groups. In addition, intakes of PUFA $^{(7,9,11,13-16)}$ and monounsaturated fat (MUFA) ${ }^{(15-17)}$ are often reported to be less than the desired intake levels ( $\geq 6 \%$ and $\geq 12 \%$ for PUFA and MUFA, respectively).

The main contributors to fat intakes vary widely between countries $^{(18)}$. In general, the main contributors to fat intakes are meat ${ }^{(19,20)}$ and meat products ${ }^{(7,13,18,21-24)}$, milk and milk products $^{(19,24,25)}$ and fats and oils ${ }^{(13,18,21,22,24-26)}$. In addition, the main contributors to total fat and the individual fatty intakes vary.

Dietary intake surveys facilitate the analysis of fat intakes of a population to identify where population goals and dietary targets are not being achieved. Currently, there are no accurate estimates of SFA, MUFA and PUFA intakes in children, teenagers and adults in Ireland. The aims of the present paper are to provide the first data on estimates of current intakes and main food sources of SFA, MUFA and PUFA in Irish children (aged 5-12 years), teenagers (aged 13-17 years) and adults (aged 18-64 years) and to analyse compliance with current dietary recommendations. 


\section{Methods}

\section{Population samples}

The analysis for the present paper is based on data from the cross-sectional North/South Ireland Food Consumption Survey (NSIFCS), the National Children's Food Survey (NCFS) and the National Teen Food Survey (NTFS). The NSIFCS (1997-1999), NCFS (2003-2004) and NTFS (2005-2006) were carried out on representative samples of Irish adults (18-64 years, $n$ 1379), children (5-12 years, $n$ 594) and teenagers (13-17 years, $n$ 441), respectively.

\section{Methodology used in the North/South Ireland Food Consumption Survey and the National Children's Food Survey}

Data on food and beverage information in the NSIFCS and the NCFS were collected using a $7 \mathrm{~d}$ food diary. These surveys used the same food quantification methods and food groups that were used in the NTFS. More detailed accounts of the sampling methods and methodology used in the $\operatorname{NSIFCS}^{(27,28)}$ and the NCFS ${ }^{(29)}$ are available elsewhere.

\section{Data collection in the National Teen Food Survey}

A $7 \mathrm{~d}$ food diary was used to collect food and beverage intake data. During the $7 \mathrm{~d}$ period, the researcher made four visits to the respondent: a training visit to show how the food diary was kept; a second visit 24-36 h into the recording period to review the diary, check for completeness and clarify details regarding specific food descriptors and quantities; a third visit 4 or $5 \mathrm{~d}$ into the recording period to check the previous 2 or $3 \mathrm{~d}$ and to encourage completion; and a final visit 1 or $2 \mathrm{~d}$ after the recording period to check the last days and to collect the diary.

The respondents were asked to record detailed information regarding the types and amounts of all foods, beverages and nutritional supplements consumed over the $7 \mathrm{~d}$ period, the cooking method used (where applicable), the brand name of foods (where appropriate) and details of recipes and any leftovers. Data were also collected on the time of each eating or drinking occasion, the respondent's definition of each eating or drinking occasion (e.g. morning snack, lunch, etc.) and the location of the preparation or source of the meal or snack consumed (e.g. home, work, takeaway etc.). Self-administered questionnaire data were obtained on sociodemographic factors and health and lifestyle parameters. The division of the sample into social class groups was based on the parents' occupation (including last main occupation for those not working or retired). All subjects were classified according to the Census 2002 occupations of the Central Statistics Office ${ }^{(30)}$.

\section{Food quantification in the National Teen Food Survey}

On the basis that different foods are best quantified using different methods and some methods of quantification are more precise than are others, a hierarchical approach to food quantification was used as follows:

1. A portable food scales (Tanita, Japan) was given to each respondent. The field worker gave detailed instructions on how to use the food scales to respondents and/or parents/guardians during the training session. This included a demonstration where the researcher weighed the respondents' typical portion of certain foods and beverages, particularly those that were consumed most commonly (e.g. ready-to-eat breakfast cereals, home-made bread).

2. A photographic food atlas developed by the Food Standards Agency in the UK was used to quantify food and beverages ${ }^{(31)}$.

3. Suggested serving sizes indicated on food labels.

4. A database of average portions of certain foods (e.g. sliced meats, takeaway foods) was compiled by the research team.

5. Food weights and average food portion sizes estimated for UK adults by the Ministry of Agriculture, Fisheries and Food ${ }^{(32)}$.

6. Household measures.

7. The researcher-estimated portion sizes based on the respondents' eating patterns.

Food quantities were defined as estimated if the field worker made an assessment of the amount likely to have been consumed based on their knowledge of the respondents' general eating habits observed during the recording period.

\section{Estimation of nutrient intake in the National Teen Food Survey}

Food intake data were analysed using the WISP ${ }^{\mathbb{C}}$ software program (Tinuviel Software, Warrington, UK). WISP $^{(C)}$ uses data from McCance and Widdowson's The Composition of Foods, fifth ${ }^{(33)}$ and sixth editions ${ }^{(34)}$ plus supplemental volumes ${ }^{(35-43)}$, to generate nutrient intake data. The food consumption database generated from the survey listed each individual food item as consumed by each respondent together with the nutrient composition for the quantity of each food consumed.

\section{Updating the fatty acid composition of foods in the databases of the three surveys}

The food intake databases for the NSIFCS, NCFS and the NTFS were not up to date regarding fatty acid composition for certain foods and work was carried out to obtain accurate estimates of SFA, MUFA and PUFA for these foods. In order to identify the foods that required accurate fatty acid data, initial investigation of the databases identified foods where the sum of total fat and the sum of SFA, MUFA and PUFA in the databases were not equal. Information about the fatty acid composition of a food was obtained from a number of sources. Where total fat content of a food was obtained from food packages and 
no information was known about SFA, MUFA and PUFA, the proportions of SFA, MUFA and PUFA of a similar food in the McCance and Widdowson's database were used. In other instances, recipes were available for the food and fatty acid information was calculated based on this. Some fatty acid information was obtained from manufacturers.

\section{Comparison of fat intakes with dietary recommendations}

The mean daily intakes of total fat, SFA, MUFA and PUFA were compared with recommended population goals in children, teenagers and adults. The population goals selected were as follows: total fat ( $\leq 33 \%$ total energy), saturated fat ( $\leq 10 \%$ total energy), monounsaturated fat ( $\geq 12 \%$ total energy) and polyunsaturated fat ( $\geq 6 \%$ total energy $)^{(3)}$. Compliance with dietary guidelines was assessed using two approaches. First, the percentage of individuals in a population who met the dietary target for each fatty acid for the whole population, for males and females and in each of the age categories was also calculated and referred to as Approach 1. However, population goals are the recommended mean intake of a population or subgroup; it is not necessary for all individuals to achieve this intake. Compliance with these population goals was also estimated by the method of Wearne and Day ${ }^{(44)}$ and referred to as Approach 2. This approach calculated the maximum size of a subgroup of the population, known as 'compliers', whose mean intake equals the population dietary recommendation.

In order to calculate the percentage of compliers with the recommendation, the mean daily nutrient intakes for individuals were ranked in ascending order from lowest to highest. For example, in the case of the percentage of total energy from fat (and saturated fat) recommendations, the mean intake of the compliers group was calculated by starting with the individual with the lowest mean percentage of total energy from fat (and SFA) intake and including subsequent individuals in the calculation of a group mean intake until the addition of one or more individuals caused the group mean to exceed the percentage of total energy from fat (and saturated fat) target. The same approach was used for MUFA and PUFA, except that mean daily intakes for each individual were ranked in descending order from highest to lowest and successive individuals added until the addition of the next individual caused the group mean to fall below the population target. The percentage of children, teenagers and adults who were 'compliers' with each recommendation was then calculated.

The percentage contribution of the major food groups to total fat, SFA, MUFA and PUFA was calculated. Finally, the data were categorised into quartiles of percentage of total energy from fat and the intake of total fat, SFA, MUFA and PUFA, and the percentage contribution of the three fatty acids to total fat intake, was calculated for each quartile.

\section{Under-reporting of food intake in the North/South Ireland Food Consumption Survey}

As with any dietary survey where food intake is selfreported, there is evidence of misreporting, in particular under-reporting, as was found in the NSIFCS ${ }^{(45)}$. Underreporting can affect the validity of the results. The analysis of the NSIFCS was carried out excluding under-reporters of energy intake, identified as having a ratio of energy intake to BMR of less than $1 \cdot 05^{(46)}$. After the exclusion of under-reporters, the final sample contained 1097 subjects. Energy under-reporting was not analysed for children or teenagers.

\section{Statistical analyses}

All statistical analyses were carried out using the SPSS ${ }^{\circledR}$ for Windows ${ }^{\mathrm{TM}}$ statistical software package version $12 \cdot 0$ (SPSS Inc., Chicago, IL, USA). Significant differences in the mean daily intake of total fat, SFA, MUFA and PUFA expressed as a percentage of total energy were identified by independent $t$ tests. One-way ANOVA was used to test for significant differences $(P<0 \cdot 05)$ in the mean percentage contribution of SFA, MUFA and PUFA to total fat intake across the quartiles of fat intake. Equality of variance was assessed using Levene's test, which determined which post hoc test was used. For groups of equal variance, the Scheffe post hoc test was used to determine significant differences between the means for each quartile. For values that did not comply with Levene's test for homogeneity of variance, the Tamhane post hoc multiple comparisons test was used to identify significant differences between the means ${ }^{(47)}$.

\section{Results}

Table 1 presents the mean daily intake of fat and fatty acids ( $\mathrm{g} / \mathrm{d}$ and \% total energy) and P:S ratio by sex and age group in Irish children and teenagers. Mean daily intake of total fat ( $\%$ energy) in children was $33.9 \%$, of which $14 \cdot 7 \%$ was SFA, $11 \cdot 6 \%$ was MUFA and $4.9 \%$ was PUFA. In children, the percentage energy intake of total fat $(P<0.05)$, MUFA $(P<0.05)$ and PUFA $(P<0 \cdot 01)$ was significantly higher in girls than in boys and PUFA $(\%$ energy) increased significantly $(P<0.05)$ with age in girls only. The mean daily P:S ratio was 0.35 in children and $0 \cdot 42$ in teenagers. Mean daily intake of total fat (\% energy) in teenagers was $35 \cdot 7 \%$, of which $14 \cdot 4 \%$ was SFA, $12 \cdot 7 \%$ was MUFA and $5 \cdot 8 \%$ was PUFA. Percentage of total energy from PUFA was significantly higher $(P<0 \cdot 05)$ for teenage girls compared with teenage boys.

The mean daily intake of fat and fatty acids (g/d and \% total energy) and P:S ratio by sex and age group in Irish adults are shown in Table 2 . The mean daily intake of total fat (\% energy) was $35 \cdot 8 \%$, of which $14 \cdot 0 \%$ was SFA, $12 \cdot 0 \%$ was MUFA and $7 \cdot 0 \%$ was PUFA. Percentage of total energy from total fat $(P<0 \cdot 001)$, SFA $(P<0 \cdot 01)$, 
Table 1 Intake of total fat, SFA, MUFA and PUFA ( $\mathrm{g} / \mathrm{d}$ and \% of total energy, $\% \mathrm{TE}$ ) and the polyunsaturated to saturated fat (P:S) ratio in Irish childrent and teenagersł by age and sex group

\begin{tabular}{|c|c|c|c|c|c|c|c|c|c|c|c|c|c|c|c|c|c|}
\hline & & & & \multicolumn{7}{|c|}{ Males } & \multicolumn{7}{|c|}{ Females } \\
\hline & \multicolumn{3}{|c|}{ Total population } & \multicolumn{2}{|c|}{ Total group } & \multicolumn{2}{|c|}{ Age group 1} & \multicolumn{2}{|c|}{ Age group 2} & \multirow[b]{2}{*}{$P \|$} & \multicolumn{2}{|c|}{ Total group } & \multicolumn{2}{|c|}{ Age group 1} & \multicolumn{2}{|c|}{ Age group 2} & \multirow[b]{2}{*}{$P \|$} \\
\hline & Mean & SD & $P \S$ & Mean & SD & Mean & SD & Mean & SD & & Mean & SD & Mean & SD & Mean & SD & \\
\hline \multicolumn{18}{|l|}{ Total fat $(g / d)$} \\
\hline Children & $63 \cdot 2$ & $16 \cdot 5$ & $\star \star *$ & $65 \cdot 5$ & $17 \cdot 9$ & $60 \cdot 7^{a}$ & $16 \cdot 6$ & $70 \cdot 2^{b}$ & $17 \cdot 8$ & $\star * \star$ & $60 \cdot 9$ & $14 \cdot 7$ & $58 \cdot 2^{a}$ & $13 \cdot 5$ & $63 \cdot 5^{b}$ & $15 \cdot 4$ & ** \\
\hline Teenagers & $78 \cdot 8$ & $26 \cdot 8$ & $\star \star \star$ & $89 \cdot 2$ & $26 \cdot 8$ & $85 \cdot 1$ & $23 \cdot 8$ & $92 \cdot 3$ & $28 \cdot 5$ & * & $68 \cdot 1$ & $22 \cdot 1$ & $67 \cdot 2$ & $17 \cdot 9$ & $68 \cdot 7$ & $24 \cdot 9$ & NS \\
\hline \multicolumn{18}{|l|}{ SFA (g/d) } \\
\hline Children & $27 \cdot 3$ & $7 \cdot 8$ & $\star \star$ & $28 \cdot 4$ & $8 \cdot 5$ & $26 \cdot 5^{a}$ & $7 \cdot 9$ & $30 \cdot 3^{b}$ & $8 \cdot 6$ & $\star \star \star *$ & $26 \cdot 2$ & $6 \cdot 9$ & $25 \cdot 6$ & $6 \cdot 6$ & $26 \cdot 9$ & $7 \cdot 1$ & NS \\
\hline Teenagers & $32 \cdot 0$ & $12 \cdot 3$ & $\star \star * \star$ & $36 \cdot 7$ & $12 \cdot 4$ & $35 \cdot 3$ & $12 \cdot 1$ & $37 \cdot 7$ & $12 \cdot 6$ & NS & $27 \cdot 2$ & $10 \cdot 2$ & $27 \cdot 0$ & $8 \cdot 3$ & $27 \cdot 3$ & $11 \cdot 4$ & NS \\
\hline \multicolumn{18}{|l|}{ MUFA $(\mathrm{g} / \mathrm{d})$} \\
\hline Children & $21 \cdot 6$ & $6 \cdot 0$ & $\star \star \star ~$ & $22 \cdot 5$ & $6 \cdot 6$ & $20 \cdot 6^{a}$ & $6 \cdot 0$ & $24 \cdot 3^{b}$ & $6 \cdot 7$ & $\star \star \star *$ & $20 \cdot 8$ & $5 \cdot 2$ & $19 \cdot 6^{\mathrm{a}}$ & $4 \cdot 7$ & $21 \cdot 9^{b}$ & $5 \cdot 4$ & $\star \star \star *$ \\
\hline Teenagers & $28 \cdot 0$ & $9 \cdot 7$ & $\star * \star$ & $31 \cdot 6$ & $9 \cdot 9$ & $29 \cdot 7$ & $8 \cdot 6$ & $33 \cdot 0$ & $10 \cdot 6$ & * & $24 \cdot 4$ & $7 \cdot 9$ & $24 \cdot 2$ & $6 \cdot 5$ & $24 \cdot 5$ & $8 \cdot 8$ & NS \\
\hline \multicolumn{18}{|l|}{ PUFA (g/d) } \\
\hline Children & $9 \cdot 2$ & $3 \cdot 4$ & NS & $9 \cdot 4$ & $3 \cdot 4$ & $8 \cdot 6^{a}$ & $3 \cdot 1$ & $10 \cdot 2^{b}$ & $3 \cdot 4$ & $\star \star \star *$ & $9 \cdot 0$ & $3 \cdot 4$ & $8 \cdot 3^{a}$ & $3 \cdot 1$ & $9 \cdot 6^{\mathrm{b}}$ & 3.5 & ** \\
\hline Teenagers & $12 \cdot 6$ & $5 \cdot 1$ & $* * *$ & $14 \cdot 0$ & $5 \cdot 5$ & $13 \cdot 2$ & $4 \cdot 4$ & $14 \cdot 7$ & $6 \cdot 1$ & * & $11 \cdot 1$ & $4 \cdot 3$ & $10 \cdot 7$ & $3 \cdot 7$ & $11 \cdot 5$ & $4 \cdot 7$ & NS \\
\hline \multicolumn{18}{|c|}{ Total fat (\%TE) } \\
\hline Children & 33.9 & $4 \cdot 2$ & * & $33 \cdot 4$ & $4 \cdot 4$ & 33.5 & $4 \cdot 3$ & $33 \cdot 3$ & $4 \cdot 5$ & NS & $34 \cdot 5$ & $4 \cdot 0$ & $34 \cdot 4$ & 3.9 & $34 \cdot 5$ & $4 \cdot 2$ & NS \\
\hline Teenagers & $35 \cdot 7$ & $5 \cdot 0$ & NS & $35 \cdot 5$ & $5 \cdot 2$ & $35 \cdot 7$ & 4.9 & $35 \cdot 3$ & $5 \cdot 5$ & NS & 35.9 & $4 \cdot 8$ & $36 \cdot 1$ & $4 \cdot 6$ & $35 \cdot 7$ & $5 \cdot 0$ & NS \\
\hline \multicolumn{18}{|l|}{ SFA (\%TE) } \\
\hline Children & $14 \cdot 7$ & $2 \cdot 5$ & NS & $14 \cdot 5$ & $2 \cdot 5$ & $14 \cdot 6$ & $2 \cdot 6$ & $14 \cdot 3$ & $2 \cdot 4$ & NS & $14 \cdot 9$ & $2 \cdot 5$ & $15 \cdot 1$ & $2 \cdot 5$ & $14 \cdot 6$ & $2 \cdot 3$ & NS \\
\hline Teenagers & $14 \cdot 4$ & $2 \cdot 7$ & NS & $14 \cdot 5$ & $2 \cdot 8$ & $14 \cdot 7$ & $2 \cdot 8$ & $14 \cdot 4$ & $2 \cdot 9$ & NS & $14 \cdot 2$ & $2 \cdot 5$ & $14 \cdot 4$ & $2 \cdot 3$ & $14 \cdot 0$ & $2 \cdot 7$ & NS \\
\hline \multicolumn{18}{|l|}{ MUFA (\%TE) } \\
\hline Children & $11 \cdot 6$ & $1 \cdot 8$ & * & $11 \cdot 4$ & $1 \cdot 9$ & $11 \cdot 4$ & $1 \cdot 8$ & $11 \cdot 6$ & $2 \cdot 1$ & NS & $11 \cdot 8$ & $1 \cdot 6$ & $11 \cdot 6$ & 1.5 & 11.9 & $1 \cdot 7$ & NS \\
\hline Teenagers & $12 \cdot 7$ & $2 \cdot 2$ & NS & $12 \cdot 6$ & $2 \cdot 3$ & $12 \cdot 5$ & $2 \cdot 2$ & $12 \cdot 6$ & $2 \cdot 3$ & NS & $12 \cdot 9$ & $2 \cdot 2$ & $13 \cdot 1$ & $2 \cdot 2$ & $12 \cdot 8$ & $2 \cdot 2$ & NS \\
\hline \multicolumn{18}{|l|}{ PUFA (\%TE) } \\
\hline Children & $4 \cdot 9$ & $1 \cdot 3$ & $* \star$ & $4 \cdot 8$ & $1 \cdot 2$ & $4 \cdot 7$ & $1 \cdot 3$ & $4 \cdot 8$ & $1 \cdot 2$ & NS & $5 \cdot 1$ & $1 \cdot 3$ & $4 \cdot 9^{a}$ & $1 \cdot 3$ & $5 \cdot 2^{b}$ & $1 \cdot 4$ & * \\
\hline Teenagers & $5 \cdot 8$ & $1 \cdot 6$ & * & $5 \cdot 6$ & $1 \cdot 6$ & $5 \cdot 6$ & $1 \cdot 6$ & $5 \cdot 6$ & $1 \cdot 5$ & NS & $5 \cdot 9$ & $1 \cdot 6$ & $5 \cdot 8$ & $1 \cdot 6$ & $6 \cdot 0$ & $1 \cdot 6$ & NS \\
\hline \multicolumn{18}{|l|}{$\mathrm{P}: \mathrm{S}$ ratio } \\
\hline Children & 0.35 & $0 \cdot 12$ & NS & 0.34 & $0 \cdot 12$ & 0.34 & 0.12 & 0.35 & $0 \cdot 11$ & NS & 0.35 & $0 \cdot 12$ & $0.34^{a}$ & $0 \cdot 12$ & $0.37^{b}$ & $0 \cdot 12$ & * \\
\hline Teenagers & 0.42 & $0 \cdot 14$ & & 0.40 & $0 \cdot 14$ & 0.40 & $0 \cdot 10$ & 0.40 & $0 \cdot 13$ & NS & 0.43 & 0.14 & 0.41 & $0 \cdot 13$ & 0.45 & $0 \cdot 15$ & NS \\
\hline
\end{tabular}

${ }^{\mathrm{a}, \mathrm{b}}$ Mean values with unlike superscript letters were significantly different.

tChildren ( $n$ 594): boys ( $n$ 293), girls ( $n$ 301). Age group 1 is $5-8$ years old (total: $n$ 296, boys: $n 145$, girls: $n$ 151); age group 2 is $9-12$ years old (total: $n$ 298, boys: $n$ 148, girls: $n$ 150).

łTeenagers ( $n$ 441): boys ( $n$ 224), girls ( $n$ 217). Age group 1 is 13-14 years old (total: $n$ 188, boys: $n$ 95, girls: $n$ 93); age group 2 is $15-17$ years old (total: $n$ 253, boys: $n 129$, girls: $n 124$ )

§For comparison of means between all males and all females: ${ }^{\star} P<0.05,{ }^{\star \star} P<0.01,{ }^{\star \star \star} P<0.001$ (NS, $\left.P \geq 0.05\right)$.

IIFor comparison of means between age groups within each sex: ${ }^{\star} P<0.05,{ }^{\star \star} P<0.01,{ }^{\star \star \star} P<0.001$ (NS, $P \geq 0.05$ ).

MUFA $(P<0 \cdot 05)$ and PUFA $(P<0 \cdot 001)$ were significantly higher in women than in men. The mean P:S ratio was 0.53 .

In children, the percentage of total energy from total fat, SFA, MUFA and PUFA was similar irrespective of BMI category, social class, parent's education level and location (results not shown). However, teenagers living in rural locations had significantly higher intakes of total fat $(P<0 \cdot 01)$, SFA $(P<0 \cdot 05)$ and MUFA $(P<0.05)$ in comparison to those from urban areas. Adults living in urban areas had significantly higher $(P<0 \cdot 01)$ percentage energy intakes from PUFA $(7 \cdot 2 \%)$ than those in rural area $(6 \cdot 8 \%)$. Teenagers whose parents had secondary education had significantly higher $(P<0.05)$ percentage energy intake from MUFA than those whose parents had tertiary education. In adults percentage energy intake from MUFA was significantly higher $(P<0 \cdot 01)$ in those who had primary/intermediate education than those who had tertiary education. There were no significant differences observed for fat intakes across social class categories in teenagers and adults or for BMI and marital status in adults (results not shown).

Tables 3 and 4 present the percentage of children, teenagers and adults adhering to the UK Department of Health $^{(3)}$ recommendations ( $\%$ total energy) for total fat, SFA, MUFA and PUFA according to sex and age group using Approach 1 and Approach 2. Using the first approach, the proportion of children, teenagers and adults meeting the recommendations for total fat $(41 \%, 30 \%, 28 \%)$, SFA ( $2 \%$, $4 \%, 8 \%)$, MUFA ( $41 \%, 60 \%, 52 \%)$ and PUFA (18\%, 37\%, $68 \%)$ was relatively low. There was a difference in the proportion meeting the guidelines across the age groups in children, teenagers and adults. For example, a higher percentage of children aged 5-8 years met the recommendation for total fat. Fewer children in this age group met the recommendations for MUFA and PUFA compared with those aged 9-12 years. Using the second approach, there was a higher proportion of children, teenagers and adults in compliance with total fat $(88 \%, 67 \%, 67 \%)$, MUFA (88\%, 100\%, 100\%) and PUFA (47\%, $91 \%, 100 \%)$ 


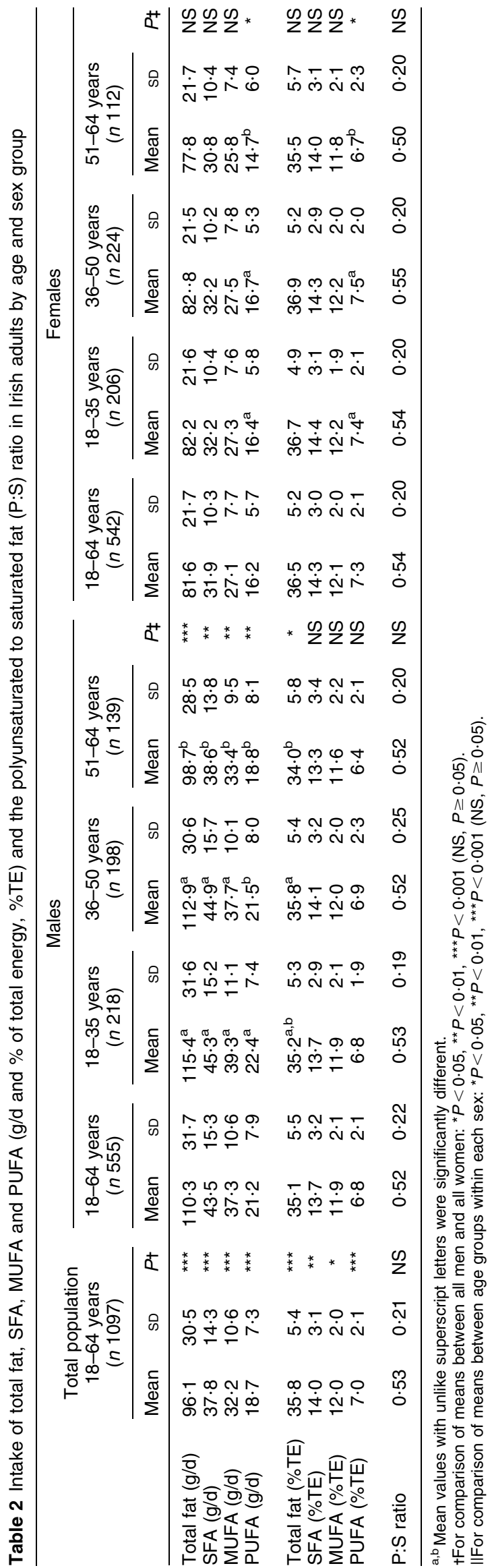

recommendations. There was a low level of compliance with the SFA recommendation (6\%, 11\%, $21 \%)$.

The percentage contributions of the major food groups to mean daily total fat, SFA, MUFA and PUFA intakes in children, teenagers and adults are shown in Table 5. Whole milk made the greatest contribution to total fat (14.8\%) in children and to SFA $(21.1 \%, 14.7 \%)$ in children and teenagers, and the second greatest contribution to MUFA $(11.3 \%)$ in children. In children, meat products, which were the most important contributor to MUFA (13.1\%) and PUFA $(11 \cdot 4 \%)$ intakes, also contributed $10.5 \%$ to total fat and $8.7 \%$ to SFA. In teenagers, the main contributor to total fat $(11.5 \%)$ and SFA (14.7\%) were meat products and whole milk, respectively. The greatest contributor to MUFA and PUFA intakes in teenagers were meat products (13.4\%) and potatoes chipped, fried and roasted $(12 \cdot 4 \%)$, respectively. In adults, the greatest contributor to total fat (9.8\%) and MUFA (12.5\%) intakes was fresh meat, while the greatest contributor to SFA and PUFA intakes was whole milk $(10 \cdot 1 \%)$ and spreading fats (other than butter and low-fat spreads) (16.3\%), respectively.

Intakes of SFA, MUFA and PUFA $(\mathrm{g} / \mathrm{d}$ and $\%$ total energy) and the percentage composition of fatty acids to dietary fat intakes across quartiles of percentage of total energy from total fat in children, teenagers and adults are reported in Table 6 . There was a significant increase $(P<0 \cdot 001)$ in the intakes of (\% energy) total fat, SFA and MUFA as fat intake increased in children, teenagers and adults. The percentage composition of total fat from SFA (teenagers only), MUFA and PUFA (teenagers and adults) was not significantly different across the four groups of fat intake.

\section{Discussion}

The results of the present study are in agreement with others which have reported high intakes (\% energy) of total fat ${ }^{(1,8,10,16,23,48-51)}$ and SFA ${ }^{(8,10,15,23,48,49,51,52)}$ in children, teenagers and adults and also concur with studies that have shown low intakes of MUFA $^{(15,23,52)}$ and PUFA $^{(15,48,49,51,52)}$ in children and teenagers in relation to recommendations.

The intakes of fat, SFA, MUFA and PUFA vary widely between studies carried out in different countries in children, teenagers and adults. For example, the mean daily intake of total fat in children in our study (33.9\%) was lower than those reported in British children by Glynn et al. ${ }^{(51)}$ (35.3\% in boys, $36 \cdot 1 \%$ in girls) and in American children (aged 1-10 years) by Ganji et al. ${ }^{(48)}$ (34-38\%) and higher than the intake reported in American children (mean age 8.9 years) by Stewart et $a l^{(15)}(31 \cdot 1 \%)$. The mean intake of SFA $(14 \cdot 7 \%)$ in children our study was similar to that found by Glynn et al. $^{(51)}$ (14.3\% and $14 \cdot 6 \%$ in boys and girls) and Ganji et al. ${ }^{(48)}(12-15 \%)$. Children's intakes of PUFA in our study $(4 \cdot 9 \%)$ were also similar to those reported by several 
Table 3 Percentage of Irish childrent and teenagersł adhering to current UK dietary recommendations for total fat, SFA, MUFA and PUFA by age and sex group using Approach 1 (\% meeting the target) and Approach 2 (\% compliers with the target)

\begin{tabular}{|c|c|c|c|c|c|c|c|c|c|}
\hline & \multicolumn{3}{|c|}{ Total population } & \multicolumn{3}{|c|}{ Males } & \multicolumn{3}{|c|}{ Females } \\
\hline & Total group & Age group 1 & Age group 2 & Total group & Age group 1 & Age group 2 & Total group & Age group 1 & Age group 2 \\
\hline & \multicolumn{9}{|c|}{ Approach 1: Proportion of individuals who met target (\%) } \\
\hline$\%$ total energy from fat (target $\leq 33 \%$ ) $\S$ & & & & & & & & & \\
\hline Children & 41 & 42 & 40 & 47 & 48 & 47 & 35 & 36 & 33 \\
\hline Teenagers & 30 & 28 & 31 & 30 & 28 & 31 & 29 & 29 & 31 \\
\hline \multicolumn{10}{|l|}{$\%$ total energy from SFA (target $\leq 10 \%) \S$} \\
\hline Children & 2 & 2 & 3 & 3 & 2 & 3 & 2 & 2 & 2 \\
\hline Teenagers & 4 & 3 & 5 & 6 & 6 & 5 & 3 & 0 & 5 \\
\hline \multicolumn{10}{|l|}{$\%$ total energy from MUFA (target $\geq 12 \%$ ) $\S$} \\
\hline Children & 41 & 38 & 45 & 37 & 33 & 41 & 46 & 42 & 49 \\
\hline Teenagers & 60 & 60 & 61 & 56 & 53 & 58 & 65 & 67 & 63 \\
\hline \multicolumn{10}{|l|}{$\%$ total energy from PUFA (target $\geq 6 \%$ ) } \\
\hline Children & 18 & 16 & 21 & 15 & 15 & 16 & 22 & 17 & 27 \\
\hline \multirow[t]{2}{*}{ Teenagers } & 37 & 37 & 37 & 33 & 35 & 31 & 41 & 38 & 43 \\
\hline & \multicolumn{9}{|c|}{ Approach 2: Proportion of individuals in 'compliers' group (\%) } \\
\hline$\%$ total energy from fat (target $\leq 33 \%) \S$ & & & & & & & & & \\
\hline Children & 88 & 88 & 89 & 90 & 90 & 91 & 86 & 85 & 87 \\
\hline Teenagers & 67 & 68 & 66 & 68 & 71 & 67 & 66 & 66 & 66 \\
\hline \multicolumn{10}{|l|}{$\%$ total energy from SFA (target $\leq 10 \%) \S$} \\
\hline Children & 6 & 5 & 6 & 8 & 8 & 7 & 4 & 3 & 5 \\
\hline Teenagers & 11 & 8 & 13 & 11 & 10 & 12 & 11 & 6 & 15 \\
\hline \multicolumn{10}{|l|}{$\%$ total energy from MUFA (target $\geq 12 \%$ ) $\S$} \\
\hline Children & 88 & 89 & 88 & 85 & 86 & 84 & 92 & 91 & 92 \\
\hline Teenagers & 100 & 100 & 100 & 100 & 100 & 100 & 100 & 100 & 100 \\
\hline \multicolumn{10}{|l|}{$\%$ total energy from PUFA (target $\geq 6 \%$ ) $\S$} \\
\hline Children & 47 & 45 & 48 & 42 & 43 & 40 & 51 & 46 & 57 \\
\hline Teenagers & 91 & 89 & 92 & 88 & 87 & 89 & 93 & 90 & 94 \\
\hline
\end{tabular}

tChildren ( $n$ 594): boys ( $n$ 293), girls ( $n$ 301). Age group 1 is $5-8$ years old (total: $n$ 296, boys: $n 145$, girls: $n$ 151); age group 2 is 9-12 years old (total: $n$ 298, boys: $n$ 148, girls: $n$ 150).

†Teenagers ( $n$ 441): boys $(n$ 224), girls $(n$ 217). Age group 1 is $13-14$ years old (total: $n$ 188, boys: $n$ 95, girls: $n$ 93); age group 2 is $15-17$ years old (total: $n$ 253, boys: $n 129$, girls: $n$ 124).

(1991) ${ }^{(3)}$ 


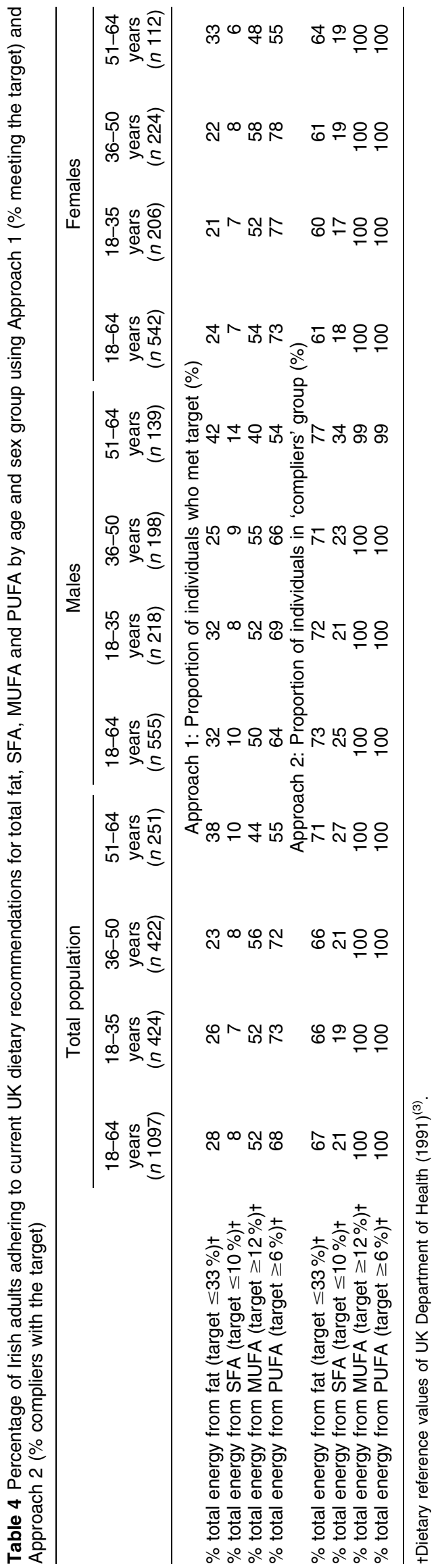

studies (Stewart et $a l^{(15)}: 4 \cdot 9 \%$, Glynn et al. ${ }^{(51)}: 5 \cdot 2 \%$ in boys and $5 \cdot 4 \%$ in girls, Tonstad and Sivertsen ${ }^{(52)}: 3 \cdot 7-5 \cdot 6 \%$ ).

The mean daily intake of total fat in teenagers in our study $(35.7 \%)$ was similar to those reported in Turkish adolescents (aged 12-17 years, 35.5\%) ${ }^{(6)}$ and in Flemish adolescents (aged 13-18 years, 35.7\%) ${ }^{(12)}$. The mean intake of SFA in the NTFS $(14.4 \%)$ was lower than that reported in Flemish adolescents (15.4\%) by Matthys et $a l^{(12)}$ and higher than the intake reported in Greek adolescents $(13 \cdot 8 \%)$ by Klimis-Zacas et $a l^{(9)}$. Intake of total fat $(35 \cdot 8 \%)$ in adults in our study was similar to that found by Schothorst and Jekel ${ }^{(16)}(35 \%)$ but lower than in several other studies (Thomson et al. ${ }^{(53)}: 38 \%$, Capita and Alonso-Calleja ${ }^{(2)}$ : $\sim 39 \%$, Garcia-Arias et al. ${ }^{(5)}$ : 39.6\%). Hulshof et $a l^{(18)}$ analysed fat intakes in fourteen Western European countries and reported that SFA ranged from 10 to $19 \%$, MUFA from 9 to $12 \%$ and PUFA from 3 to $7 \%$.

Several non-dietary factors have been reported to affect the intake of fats, such as age ${ }^{(23,54)}, \operatorname{sex}^{(11,22,55,56)}$, race $^{(10,54)}$, education ${ }^{(50,52,54,57,58)}$ and income ${ }^{(57)}$. Cullen et $a{ }^{(50)}$ found that children whose fathers reported obtaining a college degree or higher had a significantly lower $(P<0.05)$ percentage energy intake from fat. In our study we did not find any difference in fat intakes across social class, parent's education level or location categories in children. No association with increasing age was found for SFA or MUFA intake in our study. We found an association between location, education level and fat intakes in teenagers and adults.

The current study used two separate approaches to assess compliance with dietary population guidelines. Approach 1 examined the proportion of individuals who met fat recommendations. However, these recommendations are population averages established for the entire population and it is not necessary for all individuals to achieve these recommendations. As a result, the proportion of children, teenagers and adults who met the recommendations for fat was low. Approach 2 took this into account and examined the proportion of the population whose mean intakes are equal to the population dietary recommendations. This approach provides a more accurate picture of the level of compliance with population recommendations.

The results of our study are similar to several other studies which have found that whole milk $^{(19,24,25)}$ and meat products ${ }^{(7,13,18,21,24)}$ are the greatest contributors to total fat intakes and among the main contributors to SFA, MUFA and PUFA intakes. In addition we found that sugars, confectionery and preserves were significant contributors to total fat, SFA and MUFA intakes in children and teenagers and potatoes chipped, fried and roasted were significant contributors to PUFA intakes in children, teenagers and adults.

The P:S ratio has been shown to be strongly and inversely related to CHD risk in adults ${ }^{(59)}$. In their report Diet and Cardiovascular Disease, the UK Department of Health $^{(60)}$ recommended that the P:S ratio should be 
Table 5 Percentage contribution of food groups to mean daily total fat, SFA, MUFA and PUFA intakes in Irish children, teenagers and adults

\begin{tabular}{|c|c|c|c|c|c|c|c|c|c|c|c|c|}
\hline \multirow[b]{3}{*}{ Food group } & \multicolumn{4}{|c|}{ Children } & \multicolumn{4}{|c|}{ Teenagers } & \multicolumn{4}{|c|}{ Adults } \\
\hline & \multicolumn{4}{|c|}{$\%$ contribution to } & \multicolumn{4}{|c|}{$\%$ contribution to } & \multicolumn{4}{|c|}{$\%$ contribution to } \\
\hline & Total fat & SFA & MUFA & PUFA & Total fat & SFA & MUFA & PUFA & Total fat & SFA & MUFA & PUFA \\
\hline Fresh meat & $3 \cdot 1$ & $2 \cdot 6$ & $3 \cdot 9$ & $2 \cdot 9$ & $4 \cdot 6$ & $4 \cdot 1$ & $5 \cdot 5$ & $3 \cdot 7$ & $9 \cdot 8$ & $9 \cdot 6$ & $12 \cdot 5$ & $6 \cdot 6$ \\
\hline $\begin{array}{l}\text { Spreading fats (other than butter and } \\
\text { low-fat spreads) }\end{array}$ & $6 \cdot 0$ & $4 \cdot 4$ & $7 \cdot 6$ & $9 \cdot 5$ & $5 \cdot 8$ & $4 \cdot 5$ & $7 \cdot 0$ & $8 \cdot 5$ & $8 \cdot 8$ & $6 \cdot 7$ & $7 \cdot 0$ & $16 \cdot 3$ \\
\hline Meat products & $10 \cdot 5$ & $8 \cdot 7$ & $13 \cdot 1$ & $11 \cdot 4$ & $11 \cdot 5$ & $10 \cdot 3$ & $13 \cdot 4$ & $11 \cdot 4$ & $7 \cdot 5$ & $7 \cdot 2$ & $9 \cdot 1$ & $5 \cdot 6$ \\
\hline Potato products & $0 \cdot 7$ & $0 \cdot 2$ & $0 \cdot 6$ & $2 \cdot 5$ & $0 \cdot 9$ & $0 \cdot 4$ & $0 \cdot 6$ & $2 \cdot 5$ & $0 \cdot 7$ & $0 \cdot 4$ & $0 \cdot 6$ & 1.9 \\
\hline Biscuits, cakes, pastries and buns & $7 \cdot 6$ & $8 \cdot 7$ & $7 \cdot 8$ & $5 \cdot 6$ & $5 \cdot 6$ & $6 \cdot 4$ & $5 \cdot 6$ & $4 \cdot 4$ & $7 \cdot 0$ & $8 \cdot 2$ & $7 \cdot 4$ & $4 \cdot 2$ \\
\hline Whole milk & $14 \cdot 8$ & $21 \cdot 1$ & $11 \cdot 3$ & $2 \cdot 9$ & $9 \cdot 8$ & $14 \cdot 7$ & $7 \cdot 2$ & $1 \cdot 7$ & $6 \cdot 5$ & $10 \cdot 1$ & $5 \cdot 8$ & $1 \cdot 0$ \\
\hline Breads and rolls & $3 \cdot 7$ & $2 \cdot 3$ & $2 \cdot 9$ & $6 \cdot 9$ & 3.5 & $2 \cdot 1$ & $2 \cdot 3$ & $5 \cdot 2$ & $4 \cdot 9$ & $3 \cdot 7$ & $3 \cdot 9$ & $7 \cdot 0$ \\
\hline Meat dishes & $4 \cdot 2$ & $3 \cdot 6$ & $4 \cdot 9$ & $3 \cdot 9$ & $5 \cdot 0$ & $4 \cdot 5$ & $5 \cdot 5$ & $4 \cdot 3$ & $4 \cdot 8$ & $4 \cdot 3$ & $5 \cdot 4$ & $1 \cdot 2$ \\
\hline Butter & $2 \cdot 1$ & $2 \cdot 8$ & $1 \cdot 6$ & $0 \cdot 6$ & $2 \cdot 2$ & $3 \cdot 1$ & $1 \cdot 7$ & $0 \cdot 6$ & $5 \cdot 1$ & $7 \cdot 8$ & $3 \cdot 9$ & $4 \cdot 3$ \\
\hline Cheeses & $3 \cdot 3$ & $4 \cdot 7$ & $2 \cdot 7$ & $0 \cdot 8$ & $4 \cdot 4$ & $6 \cdot 8$ & $3 \cdot 6$ & $0 \cdot 9$ & $4 \cdot 3$ & $6 \cdot 8$ & $3 \cdot 6$ & $1 \cdot 0$ \\
\hline Soups, sauces and other foods & $1 \cdot 7$ & $1 \cdot 0$ & $1 \cdot 3$ & $3 \cdot 1$ & $4 \cdot 0$ & $2 \cdot 0$ & $5 \cdot 0$ & $6 \cdot 5$ & $3 \cdot 6$ & $2 \cdot 3$ & $3 \cdot 1$ & $6 \cdot 5$ \\
\hline Puddings and chilled desserts & $1 \cdot 4$ & $1 \cdot 4$ & $1 \cdot 5$ & $1 \cdot 3$ & $1 \cdot 4$ & $1 \cdot 6$ & $1 \cdot 5$ & $1 \cdot 1$ & $2 \cdot 4$ & $3 \cdot 0$ & $2 \cdot 4$ & $1 \cdot 2$ \\
\hline Sugars, confectionery and preserves & $8 \cdot 3$ & $10 \cdot 3$ & $8 \cdot 6$ & $3 \cdot 4$ & $7 \cdot 8$ & $10 \cdot 1$ & $7 \cdot 9$ & $3 \cdot 2$ & $3 \cdot 5$ & $4 \cdot 8$ & $3 \cdot 6$ & $1 \cdot 1$ \\
\hline Fish, fish products and fish dishes & $1 \cdot 2$ & $0 \cdot 7$ & $1 \cdot 3$ & $2 \cdot 6$ & $1 \cdot 2$ & $0 \cdot 7$ & $1 \cdot 3$ & $2 \cdot 2$ & $4 \cdot 3$ & $2 \cdot 3$ & $5 \cdot 0$ & $6 \cdot 8$ \\
\hline Eggs and egg dishes & $1 \cdot 8$ & $1 \cdot 6$ & $2 \cdot 0$ & $1 \cdot 4$ & $1 \cdot 7$ & 1.5 & $1 \cdot 8$ & $1 \cdot 3$ & $2 \cdot 6$ & $2 \cdot 2$ & $3 \cdot 2$ & $1 \cdot 8$ \\
\hline Vegetable and pulse dishes (e.g. coleslaw) & $0 \cdot 7$ & 0.3 & 0.6 & $1 \cdot 9$ & $1 \cdot 1$ & 0.6 & 0.9 & $2 \cdot 6$ & $2 \cdot 6$ & $1 \cdot 2$ & $2 \cdot 0$ & $6 \cdot 1$ \\
\hline Savouries (e.g. pizza, quiche) & $3 \cdot 9$ & $3 \cdot 3$ & $4 \cdot 1$ & $5 \cdot 1$ & $5 \cdot 4$ & $4 \cdot 8$ & $5 \cdot 8$ & $7 \cdot 4$ & $2 \cdot 7$ & $2 \cdot 4$ & $3 \cdot 0$ & $3 \cdot 2$ \\
\hline Low-fat spreads & $1 \cdot 0$ & 0.6 & $1 \cdot 0$ & $2 \cdot 6$ & $1 \cdot 2$ & $0 \cdot 7$ & $1 \cdot 1$ & $2 \cdot 7$ & $2 \cdot 1$ & $1 \cdot 8$ & $1 \cdot 8$ & $3 \cdot 5$ \\
\hline snacks (e.g. crisps) & $6 \cdot 0$ & $4 \cdot 7$ & $6 \cdot 9$ & $8 \cdot 8$ & $5 \cdot 1$ & $4 \cdot 5$ & $5 \cdot 4$ & $5 \cdot 7$ & $2 \cdot 2$ & $2 \cdot 2$ & $2 \cdot 5$ & $2 \cdot 0$ \\
\hline Potatoes chipped, fried and roasted & $5 \cdot 8$ & $3 \cdot 9$ & $6 \cdot 9$ & $9 \cdot 9$ & $7 \cdot 7$ & $5 \cdot 4$ & $9 \cdot 1$ & $12 \cdot 4$ & $6 \cdot 1$ & $3 \cdot 5$ & $7 \cdot 1$ & $10 \cdot 5$ \\
\hline Ice cream & $2 \cdot 6$ & $4 \cdot 0$ & 1.9 & $0 \cdot 7$ & $1 \cdot 5$ & $2 \cdot 5$ & $1 \cdot 0$ & $0 \cdot 4$ & $1 \cdot 0$ & $1 \cdot 6$ & $0 \cdot 8$ & 0.2 \\
\hline $\begin{array}{l}\text { Potatoes (e.g. mashed with milk/butter } \\
\text { added) }\end{array}$ & $0 \cdot 7$ & $0 \cdot 8$ & 0.4 & $1 \cdot 4$ & $1 \cdot 2$ & $1 \cdot 3$ & $0 \cdot 8$ & $1 \cdot 9$ & $1 \cdot 2$ & $1 \cdot 2$ & $0 \cdot 7$ & $2 \cdot 1$ \\
\hline RTEBC & $1 \cdot 3$ & 0.9 & $0 \cdot 8$ & $2 \cdot 9$ & $1 \cdot 0$ & 0.8 & 0.6 & $2 \cdot 1$ & $0 \cdot 7$ & 0.4 & 0.5 & $1 \cdot 2$ \\
\hline Otherst & $7 \cdot 6$ & $7 \cdot 4$ & $6 \cdot 3$ & $7 \cdot 9$ & $7 \cdot 6$ & $7 \cdot 8$ & $7 \cdot 0$ & $8 \cdot 4$ & $5 \cdot 6$ & $6 \cdot 3$ & $5 \cdot 1$ & $4 \cdot 7$ \\
\hline Total & $100 \cdot 0$ & $100 \cdot 0$ & $100 \cdot 0$ & $100 \cdot 0$ & $100 \cdot 0$ & $100 \cdot 0$ & $100 \cdot 0$ & $100 \cdot 0$ & $100 \cdot 0$ & $100 \cdot 0$ & $100 \cdot 0$ & $100 \cdot 0$ \\
\hline
\end{tabular}

RTEBS, ready-to-eat breakfast cereals.

tOther food groups include breakfast cereals, cream, fruit, low-fat milk, non-alcoholic beverages, rice and pasta, yoghurts and vegetables.

Table 6 Intake of total fat, SFA, MUFA and PUFA ( $\mathrm{g} / \mathrm{d}$ and \% of total energy, \%TE), percentage composition of fatty acids to dietary fat intake and the polyunsaturated to saturated fat (P:S) ratio across quartiles of \%TE from total fat in Irish children, teenagers and adults

\begin{tabular}{|c|c|c|c|c|c|c|c|c|c|c|c|c|c|c|c|}
\hline & \multicolumn{5}{|c|}{ Children ( $n$ 594) } & \multicolumn{5}{|c|}{ Teenagers ( $n$ 441) } & \multicolumn{5}{|c|}{ Adults ( $n$ 1097) } \\
\hline & \multicolumn{4}{|c|}{ Quartile of \%TE from total fat } & \multicolumn{5}{|c|}{ Quartile of $\%$ TE from total fat } & \multicolumn{5}{|c|}{ Quartile of \%TE from total fat } & \\
\hline & $\begin{array}{l}\text { Lowest } \\
\text { (n 148) }\end{array}$ & $\begin{array}{l}\text { Low } \\
(n 148)\end{array}$ & $\begin{array}{r}\text { Medium } \\
(n \text { 150) }\end{array}$ & $\begin{array}{l}\text { High } \\
(n \text { 148) }\end{array}$ & $P+$ & $\begin{array}{l}\text { Lowest } \\
\text { ( } n \text { 110) }\end{array}$ & $\begin{array}{l}\text { Low } \\
(n 110)\end{array}$ & $\begin{array}{c}\text { Medium } \\
(n \text { 111) }\end{array}$ & $\begin{array}{l}\text { High } \\
(n 110)\end{array}$ & $P+$ & $\begin{array}{l}\text { Lowest } \\
(n \text { 135) }\end{array}$ & $\begin{array}{l}\text { Low } \\
(n 136)\end{array}$ & $\begin{array}{c}\text { Medium } \\
(n \text { 136) }\end{array}$ & $\begin{array}{l}\text { High } \\
(n \text { 135) }\end{array}$ & $P+$ \\
\hline $\begin{array}{l}\text { Total fat }(g / d) \\
\text { SFA }(g / d) \\
\text { MUFA }(g / d) \\
\text { PUFA }(g / d)\end{array}$ & $\begin{array}{c}52 \cdot 2^{\mathrm{a}} \\
22 \cdot 5^{\mathrm{a}} \\
17 \cdot 6^{\mathrm{a}} \\
7 \cdot 7^{\mathrm{a}}\end{array}$ & $\begin{array}{r}58 \cdot 4^{\mathrm{b}} \\
24 \cdot 7^{\mathrm{b}} \\
20 \cdot 1^{\mathrm{b}} \\
8 \cdot 9^{\mathrm{b}}\end{array}$ & $\begin{array}{c}66 \cdot 5^{\mathrm{c}} \\
28 \cdot 8^{\mathrm{c}} \\
22 \cdot 6^{\mathrm{c}} \\
9 \cdot 6^{\mathrm{b}, \mathrm{c}}\end{array}$ & $\begin{array}{l}75 \cdot 5^{d} \\
33 \cdot 1^{d} \\
26 \cdot 0^{d} \\
10 \cdot 6^{c}\end{array}$ & $\begin{array}{l}* * * \\
\star * \\
\star * * \\
\star *\end{array}$ & $\begin{array}{r}59 \cdot 6^{\mathrm{a}} \\
23 \cdot 8^{\mathrm{a}} \\
21 \cdot 0^{\mathrm{a}} \\
9 \cdot 8^{\mathrm{a}}\end{array}$ & $\begin{array}{l}74 \cdot 1^{\mathrm{b}} \\
30 \cdot 0^{\mathrm{b}} \\
26 \cdot 3^{\mathrm{b}} \\
11 \cdot 8^{\mathrm{b}}\end{array}$ & $\begin{array}{l}85 \cdot 1^{c} \\
35 \cdot 2^{c} \\
30 \cdot 2^{c} \\
13 \cdot 2^{b}\end{array}$ & $\begin{array}{l}96 \cdot 4^{d} \\
39 \cdot 1^{c} \\
34 \cdot 6^{d} \\
15 \cdot 7^{c}\end{array}$ & $\begin{array}{l}* \star \\
\star \star \\
\star \star \\
\star \star\end{array}$ & $\begin{array}{l}61 \cdot 8^{\mathrm{a}} \\
23 \cdot 2^{\mathrm{a}} \\
20 \cdot 6^{\mathrm{a}} \\
12 \cdot 5^{\mathrm{a}}\end{array}$ & $\begin{array}{l}78 \cdot 1^{b} \\
30 \cdot 6^{b} \\
25 \cdot 9^{b} \\
15 \cdot 4^{b}\end{array}$ & $\begin{array}{l}88 \cdot 3^{c} \\
34 \cdot 6^{c} \\
29 \cdot 7^{c} \\
17 \cdot 5^{c}\end{array}$ & $\begin{array}{l}98 \cdot 1^{d} \\
39 \cdot 3^{d} \\
32 \cdot 2^{d} \\
19 \cdot 3^{c}\end{array}$ & $\begin{array}{l}* \star * \\
\star * \\
* \\
* *\end{array}$ \\
\hline $\begin{array}{l}\text { Total fat (\%TE) } \\
\text { SFA (\%TE) } \\
\text { MUFA (\%TE) } \\
\text { PUFA (\%TE) }\end{array}$ & $\begin{array}{r}28 \cdot 6^{\mathrm{a}} \\
12 \cdot 3^{\mathrm{a}} \\
9 \cdot 6^{\mathrm{a}} \\
4 \cdot 2^{\mathrm{a}}\end{array}$ & $\begin{array}{c}32 \cdot 6^{\mathrm{b}} \\
13 \cdot 8^{\mathrm{b}} \\
11 \cdot 2^{\mathrm{b}} \\
4 \cdot 9^{\mathrm{b}}\end{array}$ & $\begin{array}{c}35 \cdot 2^{\mathrm{c}} \\
15 \cdot 3^{\mathrm{c}} \\
12 \cdot 0^{\mathrm{c}} \\
5 \cdot 1^{\mathrm{b}, \mathrm{c}}\end{array}$ & $\begin{array}{c}39 \cdot 3^{d} \\
17 \cdot 3^{d} \\
13 \cdot 5^{d} \\
5 \cdot 5^{c}\end{array}$ & $\begin{array}{l}* * * \\
* * * \\
* * * \\
* * *\end{array}$ & $\begin{array}{c}29 \cdot 4^{\mathrm{a}} \\
11 \cdot 7^{\mathrm{a}} \\
10 \cdot 4^{\mathrm{a}} \\
4 \cdot 9^{\mathrm{a}}\end{array}$ & $\begin{array}{r}34 \cdot 1^{\mathrm{b}} \\
13 \cdot 7^{\mathrm{b}} \\
12 \cdot 1^{\mathrm{b}} \\
5 \cdot 5^{\mathrm{b}}\end{array}$ & $\begin{array}{r}37 \cdot 2^{c} \\
15 \cdot 2^{c} \\
13 \cdot 3^{c} \\
5 \cdot 8^{b}\end{array}$ & $\begin{array}{r}42 \cdot 0^{d} \\
16 \cdot 9^{d} \\
15 \cdot 2^{d} \\
6 \cdot 9^{c}\end{array}$ & $\begin{array}{l}\star \star * \\
\star \star * \\
\star \star * \\
\star \star\end{array}$ & $\begin{array}{r}29 \cdot 6^{\mathrm{a}} \\
11 \cdot 1^{\mathrm{a}} \\
9 \cdot 9^{\mathrm{a}} \\
6 \cdot 0^{\mathrm{a}}\end{array}$ & $\begin{array}{r}35 \cdot 1^{\mathrm{b}} \\
13 \cdot 7^{\mathrm{b}} \\
11 \cdot 6^{\mathrm{b}} \\
7 \cdot 0^{\mathrm{b}}\end{array}$ & $\begin{array}{r}38 \cdot 6^{c} \\
15 \cdot 1^{c} \\
12 \cdot 9^{c} \\
7 \cdot 7^{c}\end{array}$ & $\begin{array}{l}42 \cdot 9^{d} \\
17 \cdot 2^{d} \\
14 \cdot 1^{d} \\
8 \cdot 4^{c}\end{array}$ & $\begin{array}{l}\star \star * \\
\star \star * \\
\star * * \\
\star *\end{array}$ \\
\hline $\begin{array}{l}\text { SFA ( } \% \text { of dietary fat) } \\
\text { MUFA ( } \% \text { of dietary fat) } \\
\text { PUFA ( } \% \text { of dietary fat) }\end{array}$ & $\begin{array}{l}43 \cdot 1^{\mathrm{a}} \\
33 \cdot 6 \\
14 \cdot 8^{\mathrm{a}, \mathrm{b}}\end{array}$ & $\begin{array}{l}42 \cdot 4^{\mathrm{a}} \\
34 \cdot 4 \\
15 \cdot 1^{\mathrm{a}}\end{array}$ & $\begin{array}{l}43 \cdot 3^{a, b} \\
34 \cdot 1 \\
14 \cdot 4^{a \cdot b}\end{array}$ & $\begin{array}{l}43 \cdot 9^{b} \\
34 \cdot 4 \\
13 \cdot 9^{b}\end{array}$ & $\stackrel{*}{\text { NS }}$ & $\begin{array}{l}39 \cdot 7 \\
35 \cdot 2 \\
16 \cdot 6\end{array}$ & $\begin{array}{l}40 \cdot 1 \\
35 \cdot 6 \\
16 \cdot 2\end{array}$ & $\begin{array}{l}41 \cdot 0 \\
35 \cdot 7 \\
15 \cdot 7\end{array}$ & $\begin{array}{l}40 \cdot 3 \\
36 \cdot 1 \\
16 \cdot 3\end{array}$ & $\begin{array}{l}\text { NS } \\
\text { NS } \\
\text { NS }\end{array}$ & $\begin{array}{l}37 \cdot 3^{a} \\
33 \cdot 3 \\
20 \cdot 4\end{array}$ & $\begin{array}{l}39 \cdot 0^{\mathrm{a}, \mathrm{b}} \\
33 \cdot 1 \\
19 \cdot 9\end{array}$ & $\begin{array}{l}39 \cdot 0^{\mathrm{a}, \mathrm{b}} \\
33 \cdot 5 \\
20 \cdot 0\end{array}$ & $\begin{array}{l}40 \cdot 1^{b} \\
32 \cdot 8 \\
19 \cdot 6\end{array}$ & $\begin{array}{l}* * * \\
\text { NS } \\
\text { NS }\end{array}$ \\
\hline $\mathrm{P}: S$ ratio & 0.35 & $0 \cdot 37$ & $0 \cdot 34$ & $0 \cdot 30$ & NS & 0.43 & 0.42 & 0.40 & 0.42 & NS & 0.56 & 0.54 & 0.53 & 0.52 & NS \\
\hline
\end{tabular}

a,b,c,d Mean values with unlike superscript letters were significantly different.

tFor comparison of means between quartiles of \%TE from total fat within each group: ${ }^{\star} P<0.05,{ }^{* \star} P<0.01,{ }^{* \star} P<0.001$ (NS, $P \geq 0.05$ ).

between $0 \cdot 23$ and $0 \cdot 45$. The P:S ratio in our study was within this range for children $(0 \cdot 35)$ and teenagers $(0 \cdot 42)$ and is similar to the P:S ratios reported in other studies in children $^{(13,48)}$ and adolescents ${ }^{(13)}$. However the P:S ratio in adults was above this level $(0.53)$ owing to their higher PUFA intakes.
In conclusion, SFA intakes in Irish children, teenagers and adults are high with only $6 \%$ of children, $11 \%$ of teenagers and $21 \%$ of adults in compliance with the recommended daily intake. The main food groups that contributed to saturated fat intakes were whole milk; fresh meat; meat products; biscuits, cakes, buns and pastries; and 
sugars, confectionery and preserves. Further analysis would be required to identify food patterns compatible with desirable intakes of total fat, SFA, MUFA and PUFA in Irish children, teenagers and adults. In addition, further analysis is needed to provide estimates of trans fatty acid intakes in Irish children, teenagers and adults.

\section{Acknowledgements}

The study received funding from the Irish Department of Agriculture and Food.

There are no conflicts of interest. T.J. conducted the analysis for the paper. A.J.W. contributed to the analysis for the adult survey. The analysis was supervised by S.N.M. and M.J.G.

\section{References}

1. Central Statistics Office (2006) Vital Statistics 4th Quarter and Yearly Summary 2005. Dublin: Central Statistics Office.

2. Capita R \& Alonso-Calleja (2003) Intake of nutrients associated with an increased risk of cardiovascular disease in a Spanish population. Int J Food Sci Nutr 54, 57-75.

3. Department of Health (1991) Dietary Reference Values for Food Energy and Nutrients for the United Kingdom. Committee on Medical Aspects of Food Policy Report on Health and Social Subjects no. 41. London: HMSO.

4. Berenson GS, Srinivasan SR \& Nicklas TA (1998) Atherosclerosis: a nutritional disease of childhood. Am J Cardiol 82, 22T-29T.

5. Garcia-Arias MT, Villarino Rodriguez A, Garcia-Linares MC, Rocandio AM \& Garcia-Fernandez MC (2003) Daily intake of macronutrients in a group of institutionalized elderly people in Leon. Spain. Nutr Hosp 18, 87-90.

6. Öner N, Vatansever U, Garipağaoğlu M \& Karasalihoğlu S (2005) Dietary intakes among Turkish adolescent girls. Nutr Res 25, 377-386.

7. Matthys C, De Henauw S, Bellemans M \& De Maeyer M (2006) Sources of saturated fatty acids in Belgian adolescents' diet: implications for the development of food-based dietary guidelines. Br J Nutr 95, 546-554.

8. Sioen IA, Pynaert I, Matthys C, De Backer G, Van Camp J \& De Henauw S (2006) Dietary intakes and food sources of fatty acids for Belgian women, focused on $n-6$ and $n-3$ polyunsaturated fatty acids. Lipids $\mathbf{4 1}, 415-422$.

9. Klimis-Zacas DJ, Anastasia ZK, Yannakouliab M, Matalasb AL, Vassilakoub T, Papoutsakis-Tsarouhasb C, Yiannakourisc N, Polychronopoulosb E \& Passosb M (2007) Dietary intakes of Greek urban adolescents do not meet the recommendations. Nutr Res 27, 18-26.

10. Troiano RP, Briefel RR, Carroll MD \& Bialostosky K (2000) Energy and fat intakes of children and adolescents in the United States: data from the National Health and Nutrition Examination Surveys. Am J Clin Nutr 72, Suppl., 1343S-1353S.

11. Noble S \& Emmett P, the ALSPAC Study Team (2001) Food and nutrient intake in a cohort of 8-month-old infants in the south-west of England in 1993. Eur J Clin Nutr 55, 698-707.

12. Matthys C, De Henauw S, Devos C \& De Backer G (2003) Estimated energy intake, macronutrient intake and meal pattern of Flemish adolescents. Eur J Clin Nutr 57, 366-375.
13. Strain JJ, Robson PJ, Livingstone MBE, Primrose ED, Savage JM, Cran GW \& Boreham CAG (1994) Estimates of food and macronutrient intake in a random sample of Northern Ireland adolescents. Br J Nutr 72, 343-352.

14. Kersting M, Sichert-Hellert W, Alexy W, Manz F \& Schoch G (1998) Macronutrient intake of 1 to 18 year old German children and adolescents. Z Ernabrungswiss 37 , 252-259.

15. Stewart KJ, Seemans CM, McFarland LD, Weinhofer JJ \& Brown CS (1999) Dietary fat and cholesterol intake in young children compared with recommended levels. J Cardiopulm Rehabil 19, 112-117.

16. Schothorst R \& Jekel A (2000) Results of analysis of the 1994 Dutch duplicate 24-hour diet samples: fatty acids. Food Chem 70, 515-521.

17. Primorac LJ, Mandic ML, Klapec T, Folivarski K, Perl A \& Kenjeric D (2003) Fat and fatty acids intake of adults in eastern Croatia. Nutr Res 23, 1453-1461.

18. Hulshof KF, van Erp-Baart MA, Anttolainen M et al. (1999) Intake of fatty acids in western Europe with emphasis on trans fatty acids: the TRANSFAIR Study. Eur J Clin Nutr 53, $143-157$.

19. Gibney MJ (1990) Dietary guidelines: a critical appraisal. J Hum Nutr Diet 3, 245-254.

20. Hampl JS \& Betts NM (1995) Comparisons of dietary intake and sources of fat in low and high fat diets of 18-24 year olds. J Am Diet Assoc 95, 893-897.

21. Gibney MJ, Moloney M \& Shelley E (1989) The Kilkenny Health Project: food and nutrient intakes in randomly selected healthy adults. BrJ Nutr 61, 129-137.

22. Crawley HF (1993) The energy, nutrient and food intakes of teenagers aged 16-17 years in Britain. 1. Energy, macronutrients and non-starch polysaccharides. Br J Nutr 70, $15-26$.

23. Gregory J, Lowe S, Bates CJ, Prentice A, Jackson LV, Smithers G, Wenlock R \& Farron M (2000) The National Diet and Nutrition Survey: Young People Aged 4-18 Years. vol. 1: Report of the Diet and Nutrition Survey. London: The Stationery Office.

24. Harrington KE, McGowan MJ, Kiely M, Robson PJ, Livingstone MB, Morrissey PA \& Gibney MJ (2001) Macronutrient intakes and food sources in Irish adults: findings of the North/South Ireland Food Consumption Survey. Public Health Nutr 4, 1051-1060.

25. Haraldsdottir J (1999) Dietary guidelines and patterns of intake in Denmark. Br J Nutr 81, Suppl., S43-S48.

26. Staessen L, De Henauw S, De Bacquer D, De Backer G \& Van Peteghem C (1998) Fat sources in the Belgian diet. Ann Nutr Metab 42, 138-150.

27. Harrington KE, Robson PJ, Kiely M, Livingstone MBE, Lambe J, Cran GW \& Gibney MJ (2001) The North/South Ireland Food Consumption Survey: survey design and methodology. Public Health Nutr 4, 1037-1042.

28. Kiely M, Harrington K, Robson PR, Flynn A \& Cran G (2001) Sampling description and procedures used to conduct the North/South Ireland Food Consumption Survey. Public Health Nutr 4, 1029-1035.

29. Irish Universities Nutrition Alliance (2005) National Children's Food Survey. Main Report. http://www.iuna.net/ childrens_survey/ (accessed April 2008).

30. Central Statistics Office (2003) Census 2002. Principal Demographic Results. Dublin: The Stationery Office.

31. Nelson M, Atkinson M \& Meyer J (1997) A Photographic Atlas of Food Portion Sizes. London: Food Standards Agency.

32. Ministry of Agriculture, Fisheries and Food (1997) Food Portion Sizes. London: The Stationery Office.

33. Holland B, Welch AA, Unwin ID, Buss DH, Paul AA \& Southgate DAT (1995) McCance and Widdowson's The Composition of Foods, 5th ed. London: HMSO. 
34. Food Standards Agency (2002) McCance and Widdowson's The Composition of Foods, 6th summary ed. Cambridge: Royal Society of Chemistry.

35. Holland B, Unwin ID \& Buss DH (1988) Cereals and Cereal Products. Third Supplement to McCance and Widdowson's The Composition of Foods, 4th ed. London: HMSO.

36. Holland B, Unwin ID \& Buss DH (1989) Milk Products and Eggs. Fourth Supplement to McCance and Widdowson's The Composition of Foods, 4th ed. London: HMSO.

37. Holland B, Unwin ID \& Buss DH (1991) Vegetables, Herbs and Spices. Fifth Supplement to McCance and Widdowson's The Composition of Foods, 4th ed. London: HMSO.

38. Holland B, Unwin ID \& Buss DH (1992) Fruits and Nuts. First Supplement to McCance and Widdowson's The Composition of Foods, 5th ed. London: HMSO.

39. Holland B, Welch AA \& Buss DH (1992) Vegetable Dishes. Second Supplement to McCance and Widdowson's The Composition of Foods, 5th ed. London: HMSO.

40. Holland B, Brown J \& Buss DH (1993) Fish and Fish Products. Third Supplement to McCance and Widdowson's The Composition of Foods, 5th ed. London: HMSO.

41. Chan W, Brown J \& Buss DH (1994) Miscellaneous Foods. Fourth Supplement to McCance and Widdowson's The Composition of Foods, 5th ed. London: HMSO.

42. Chan W, Brown J, Lee SM \& Buss DH (1995) Meat, Poultry and Game. Fifth Supplement to McCance and Widdowson's The Composition of Foods, 5th ed. London: HMSO.

43. Chan W, Brown J, Church SM \& Buss DH (1996) Meat Products and Dishes. Sixth Supplement to McCance and Widdowson's The Composition of Foods, 5th ed. London: HMSO.

44. Wearne SJ \& Day MJ (1999) Clues for the development of food-based dietary guidelines: how are dietary targets being achieved by UK consumers? Br J Nutr 81, Suppl., S119-S126.

45. McGowan MJ, Harrington KE, Kiely M, Robson PJ, Livingston MBE \& Gibney MJ (2001) An evaluation of energy intakes and the ratio of energy intake to estimated basal metabolic rate $\left(\mathrm{EI} / \mathrm{BMR}_{\mathrm{est}}\right)$ in the North/South Ireland Food Consumption Survey. Public Health Nutr 4, 1043-1050.

46. Black AE (2000) Critical evaluation of energy intake using the Goldberg cut-off for energy intake: basal metabolic. A practical guide to its calculation, use and limitations. Int J Obes Relat Metab Disord 24, 1119-1130.

47. Coakes SJ \& Steed LG (1999) SPSS without Anguish Versions 7.0, 7.5, 8.0 for Windows. Brisbane: John Wiley and Sons.
48. Ganji V, Hampl JS \& Betts NM (1998) Macronutrients, cholesterol, sodium and fiber intakes of 1-10 year old children by age, gender and race. Nutr Res 18, 465-473.

49. Kersting M, Sichert-Hellert W, Alexy U, Manz F \& Schoch G (1998) Macronutrient intake of 1 to 18 year old German children and adolescents. Z Ernahrungswiss 37, 252-259.

50. Cullen KW, Lara KM \& de Moor C (2002) Children's dietary fat intake and fat practices vary by meal and day. J Am Diet Assoc 102, 1773-1778.

51. Glynn L, Emmett P \& Rogers I, the ALSPAC Study Team (2005) Food and nutrient intakes of a population sample of 7-year-old children in the south-west of England in 1999/ 2000 - what difference does gender make? J Hum Nutr Diet 18, 7-19.

52. Tonstad S \& Sivertsen M (1997) Relation between dietary fat and energy and micronutrient intakes. Arch Dis Child 76, 416-420.

53. Thomson $\mathrm{M}$, Fulton $\mathrm{M}$, Wood DA, Brown S, Elton RA, Birtwhistle A \& Oliver MF (1985) A comparison of the nutrient intake of some Scotsmen with dietary recommendations. Hum Nutr Appl Nutr 39, 443-455.

54. Kronsberg SS, Obarzanek E, Affenito SG, Crawford PB, Sabry ZI, Schmidt M, Striegel-Moore R, Kimm SY \& Barton BA (2003) Macronutrient intake of black and white adolescent girls over 10 years: the NHLBI Growth and Health Study. J Am Diet Assoc 103, 852-860.

55. Magarey A, Nichols J \& Boulton J (1987) Food intake at age 8. 1. Energy, macro- and micronutrients. Aust Paediatr J 23, $173-178$.

56. Soriano JM, Molto JC \& Manes DJ (2000) Dietary intake and food pattern among university students. Nutr Res 20, 1249-1258.

57. Crawford PB, Obarzanek E, Schreiber GB, Barrier P, Goldman S, Frederick MM \& Sabry ZI (1995) The effects of ethnicity, household income, and parental education on nutrient intakes of 9- and 10-year-old girls: NHLBI Growth and Health Study. Ann Epidemiol 5, 360-368.

58. Van Rossum CT, van de Mheen H, Witteman JC, Grobbee E \& Mackenbach JP (2000) Education and nutrient intake in Dutch elderly people. The Rotterdam Study. Eur J Clin Nutr 54, 159-165.

59. Hu FB, Stampfer MJ, Manson JAE, Ascherio A, Colditz A, Speizer FE, Hennekens CH \& Willett WC (1999) Dietary saturated fats and their food sources in relation to the risk of coronary heart disease in women. Am J Clin Nutr 70, 1001-1008.

60. Department of Health (1984) Diet and Cardiovascular Disease. Committee on Medical Aspects of Food Policy Report on Health and Social Subjects no. 28. London: HMSO. 